\title{
Justiça social e multiculturalismo na educaçáo: perspectiva emergente e insurgente na didática crítica intercultural
}

\author{
Marilza Vanessa Rosa Suanno ${ }^{1}$ \\ http://orcid.org/0000-0001-5892-1484 \\ Carlos Cardoso Silva ${ }^{2}$ \\ http://orcid.org/0000-0003-4594-3486 \\ Taynnara Rodrigues de Oliveira ${ }^{3}$ \\ http://orcid.org/0000-0002-6683-8792 \\ Wesley Brito Magalhães ${ }^{4}$ \\ http://orcid.org/0000-0002-5772-9041
}

${ }^{1}$ Doutora em Educação pela Universidade Católica de Brasília UCB (2015) com Doutorado Sanduíche realizado na Universidad de Barcelona UB (2011/2012). Mestre em Educação pela Pontifícia Universidade Católica de Goiás PUC Goiás (2006), revalidação do Mestrado em Ciências da Educação Superior pela Universidad de La Habana UH (2003). Graduada em Pedagogia pela Faculdade de Educação da Universidade Federal de Goiás FE/UFG (1994). Professora efetiva da Faculdade de Educação/UFG. Professora do Programa de PósGraduação em Educaçáo PPGE/FE/UFG. L\&iacut e;der do DIDAKTIKÉ - Grupo de Estudos e Pesquisas em Didática e Questóes Contemporâneas FE/UFG http://dgp.cnpq.br/dgp/espelhogrupo/7805627761585698. Membro da Rede Internacional de Escolas Criativas - RIEC (UB/Espanha). Membro do Núcleo de Formaçāo de Professores FE/UFG. Membro da Asociación de Escuelas Creativas ADEC (Madrid/ES). E-mail: marilzasuanno@uol.com.br.

2 Doutor em Educação pela Universidade Federal de Goiás (2009). Mestre em Educação Brasileira pela Universidade Federal de Goiás (2001). Especialista em Gestão da Escola Pública pela Universidade Federal de Goiás (1995). Especialista em Administração Escolar pelas Faculdades Integradas de São Gonçalo (1991). Graduado em Psicologia Pela Pontifícia Universidade Católica de Goiás (2015). Graduado em Pedagogia pela Universidade Católica de Goiás (1990). Líder do DIDAKTIKÉ - Grupo de Estudos e Pesquisas em Didática e Questóes Contemporâneas FE/UFG http://dgp.cnpq.br/dgp/espelhogrupo/7805627761585698. E-mail: carlos.cardoso27@gmail.com.

${ }^{3}$ Especialista em Docência no Ensino Superior pela FASAM (2016). Licenciada em Pedagogia pela Universidade Federal de Goiás (2019). Bacharela em Comunicação Social com habilitação em Relaçóes Públicas pela Faculdade Sul-Americana (2014). Membro do DIDAKTIKÉ - Grupo de Estudos e Pesquisas em Didática e Questôes Contemporâneas FE/UFG. E-mail: taynnara.rp@gmail.com.

${ }^{4}$ Mestrando em Educação pelo Programa de Pós-Graduação em Educação da Faculdade de Educação da Universidade Federal de Goiás PPGE/FE/UFG. Especialista em Letramento Informacional pela Faculdade de Informaçáo e Comunicaçáo da Universidade Federal de Goiás (2018). Licenciado em Pedagogia pela FE/UFG (2019). Membro do DIDAKTIKÉ - Grupo de Estudos e Pesquisas em Didática e Questóes Contemporâneas FE/UFG. E-mail: profwesleybrito@gmail.com. 


\title{
Resumo
}

Este estudo objetivou analisar os Anais do XIX ENDIPE - Encontro Nacional de Didática e Práticas de Ensino que abordou a temática "Para onde vai a didática? O enfrentamento às abordagens teóricas e desafios políticos da atualidade", ocorrido em Salvador/BA entre os dias 03 e 06 de setembro de 2018. Primeiramente, foi feito um levantamento teórico acerca do multiculturalismo e interculturalidade crítica. Em seguida, foram selecionados os artigos em que os autores utilizaram as palavras 'multiculturalismo' e 'interculturalidade' nos títulos. Ao todo, foram 20 trabalhos. A partir da leitura dos textos submetidos e das características que Vera Candau determina sobre a interculturalidade crítica, foram analisadas as seguintes categorias: a) abertura; b) reconhecimento e redistribuição; c) democracia e justiça; d) preconceito, discriminação e monocultura; e) cultura, identidade e empoderamento. Constatou-se que ao abordar a temática proposta, os artigos demonstram esforços teóricos, reflexivos e práticos insurgentes rumo a interculturalidade crítica na educação.

Palavras-chave: Educação, Didática, Multiculturalismo, Interculturalidade Crítica.

\section{Education, multiculturalism and critical intercultural teaching}

\begin{abstract}
This study aimed to analyze the Annals of the XIX ENDIPE - National Meeting of Didactics and Teaching Practices that addressed the theme "Where does didactics go? Facing today's theoretical approaches and political challenges ", which took place in Salvador / BA between September 3 and 6, 2018. First, a theoretical survey was carried out on multiculturalism and critical interculturality. Then, the articles by the authors that used words as 'multiculturalism' and 'interculturality' in the titles were selected. Altogether, there were 20 works. From the reading of the texts used and the characteristics that Vera Candau determines about a critical interculturality, the following categories were analyzed: a) openness; b) recognition and redistribution; c) democracy and justice; d) prejudice, discrimination and monoculture; e) culture, identity and empowerment. It was found that, when addressing a thematic proposal, the articles demonstrate the theoretical, reflective and practical insurgent damages, the critical interculturality in education.
\end{abstract}

Keywords: Education, Didactics, Multiculturalism, Critical Interculturality.

Introdução

Nas últimas décadas, uma perspectiva emergente no campo da educação e da didática tem buscado a afirmação dos diferentes grupos culturais na sua diferença. Tal movimento denominado multiculturalismo objetiva dar visibilidade e afirmar cada cultura. "Trabalhar as diferenças culturais constitui o foco central do multiculturalismo" (CANDAU, 2011, p. 246). Existem três abordagens do multiculturalismo: 1) multiculturalismo assimilacionista; 2) multiculturalismo diferencialista ou monoculturalismo 
plural e 3) multiculturalismo aberto e interativo, também denominado interculturalidade crítica (CANDAU, 2009; 2011).

O multicuturalimo assimilacionista parte da afirmação de que vivemos numa sociedade multicultural. De tal modo, assume uma perspectiva prescritiva ao propor políticas assimilacionistas no sentido de que todos os cidadãos se incorporem à cultura hegemônica, via integração na sociedade monocultural. No debate educacional, limita-se à argumentação em favor da política de universalização da escolarização sem questionar as relaçôes de poder e o caráter monocultural da escola, dos conteúdos escolares, do currículo, das práticas pedagógicas, dentre outros.

O multiculturalismo diferencialista ou monocultura plural (SEN, 2006) coloca a ênfase no reconhecimento da diferença para promover a expressão das diversas identidades culturais e manter suas matrizes culturais de base, pois parte da afirmação de que quando se enfatiza a assimilação termina-se por negar a diferença ou por silenciá-la.

Sobre o multicuturalimo assimilacionista e o multiculturalismo diferencialista, Vera Candau (2011, p. 246) analisa que

[...] algumas das posiçôes nesta linha terminam por assumir uma visão essencialista da formação das identidades culturais. São, então, enfatizados o acesso a direitos sociais e econômicos e, ao mesmo tempo, privilegiada a formação de comunidades culturais consideradas "homogêneas" com suas próprias organizaçóes - bairros, escolas, igrejas, clubes, associaçóes etc. Na prática, em muitas sociedades atuais terminou-se por favorecer a criação de verdadeiros apartheids socioculturais. Estas duas posições, especialmente a primeira, são as mais frequentes nas sociedades em que vivemos.

A perspectiva assumida por Vera Candau situa-se no "multiculturalismo aberto e interativo, que acentua a interculturalidade, por considerá-la a mais adequada para a construção de sociedades, democráticas e inclusivas, que articulem políticas de igualdade com políticas de identidade" (CANDAU, 2008, p. 51). São características dessa abordagem: a) promoção deliberada da interrelação entre diferentes sujeitos e grupos socioculturais presentes em uma determinada sociedade; b) rompe com uma visão essencialista das culturas e das identidades culturais. Concebe as culturas em contínuo processo de construção, desestabilização e reconstrução; c) afirma 
que nas sociedades em que vivemos os processos de hibridização cultural são intensos e mobilizadores da construção de identidades abertas, em construçáo permanente, o que supóe que as culturas não são puras, nem estáticas. "A hibridização cultural é um elemento importante na dinâmica dos diferentes grupos socioculturais" (CANDAU, 2011, p. 247); d) a consciência dos mecanismos de poder que permeiam as relaçôes culturais marcadas pelo preconceito e discriminaçáo de determinados grupos socioculturais; e) favorece o diálogo entre diversos saberes e conhecimentos, assim procura estimular o diálogo e trabalha a tensão entre universalismo e relativismo no plano epistemológico e ético; f) não desvincula as questóes da diferença e da desigualdade presentes hoje de modo particularmente conflitivo, tanto no plano mundial quanto em cada sociedade. Trata-se de ter presente esta relação, complexa e que admite diferentes configuraçóes em cada realidade, sem reduzir um polo ao outro.

Xavier, Ivenicki e Silva Junior (2018, p. 17) tendo por referência Canen (2009) e Ivenicki e Xavier (2015) destacam que "o multiculturalismo se configura como um corpo teórico e político de conhecimentos, que privilegia as identidades marginalizadas e silenciadas e que busca formas alternativas para sua incorporação no cotidiano educacional. Este campo se refere à compreensão da sociedade formada por identidades plurais, com base na diversidade de classe social, gênero, etnia, raça, padróes culturais e linguísticos, bem como outros marcadores identitários". O multiculturalismo ganha maior destaque nos debates educacionais quando trata do "tema da diferença como uma possibilidade de enriquecimento da reflexão e ação didática, seja quando destacam suas preocupaçôes pelo deslocamento do social para o cultural". (CANDAU; KOFF, 2006, p. 17).

As pesquisas no campo educacional, nas últimas duas décadas, apontam que parece não ser suficiente afirmar a existência das diferentes culturas e povos (essência do multiculturalismo assimilacionista; do multiculturalismo diferencialista ou monoculturalismo plural). Apresenta-se como urgente a construção de caminhos para o diálogo e o respeito entre as culturas, de tal modo há de construir vias para assegurar na sociedade e nas instituiçóes educativas processos democráticos e a garantia dos direitos para todos, e que tal movimento seja impulsionado pela compreensão da pluralidade de culturas e de identidades, bem como suas demandas históricas (essência do 
multiculturalismo aberto e interativo, também denominado interculturalidade crítica).

Ao analisar os artigos publicados no Anais do ENDIPE 2018, que nos títulos se denominaram reflexivos quanto a aspectos do multiculturalismo e interculturalidade, foi possível perceber que eles fazem aproximaçóes com o campo do multiculturalismo, no entanto, em sua maioria já compreendem o movimento de migração/complementação para a perspectiva da interculturalidade crítica no tratamento das temáticas educacionais, em âmbito didático, curricular e formativo.

Na literatura educacional, a expressão Educação Intercultural apresenta vários sentidos. Por se caracterizar como polissêmica, é fundamental explicitar a posição e sentido assumido nessa pesquisa, que tem por referência central as publicações de Vera Candau (2012) que: a) questiona as diferenças e desigualdades construídas ao longo da história entre diferentes grupos socioculturais, étnico-raciais, de gênero, orientação sexual, religiosos, entre outros; b) parte da afirmação de que a interculturalidade aponta à construção de sociedades que assumam as diferenças como constitutivas da democracia e sejam capazes de construir relaçôes novas, verdadeiramente igualitárias entre os diferentes grupos socioculturais; c) o que supóe empoderar aqueles que foram historicamente inferiorizados. O Grupo de Estudos sobre Cotidiano, Educação e Culturas, vinculado ao Programa de Pós-graduação em Educação da PUC-Rio, construiu coletivamente um conceito de educação intercultural, que tomamos como referência.

[...] A Educação Intercultural parte da afirmação da diferença como riqueza. Promove processos sistemáticos de diálogo entre diversos sujeitos (individuais e coletivos), saberes e práticas na perspectiva da afirmação da justiça (social, econômica, cognitiva e cultural), assim como da construção de relaçóes igualitárias entre grupos socioculturais e da democratização da sociedade, através de políticas que articulam direitos da igualdade e da diferença (CANDAU, 2014, p. 5).

Nesse sentido, a autora destaca a importância de se promover o diálogo intercultural a partir do reconhecimento dos diversos grupos socioculturais como sujeitos e atores sociais e produtores de conhecimentos, sendo este o horizonte de sentido da educação intercultural crítica. Por reconhecer distintos grupos socioculturais e seus saberes, busca empoderar grupos 
subalternizados e questionar as relaçóes de poder entre grupos e suas pautas, bem como afirmar que as diferenças, os conflitos e o diálogo são inerentes à democracia. Ao produzir análises sobre as temáticas disputadas e seus conflitos questiona o modo de produção capitalista, a lógica do mercado os princípios e ordenamentos do neoliberalismo.

$\mathrm{Na}$ análise dos trabalhos publicados nos Anais do ENDIPE 2018, foi possível identificar aproximaçóes com o multiculturalismo aberto e interativo, com a interculturalidade crítica no campo educacional. Em uma das publicaçôes, Moreira (2018) argumenta que, para Mclaren (2001), o multiculturalismo e a interculturalidade se incorporaram ao debate educacional por diversos motivos, ora porque os docentes perceberam essa necessidade, por refletirem sobre igualdade e diferença, em função das demandas da contemporaneidade impostas aos espaços educacionais, ora pela diversidade de grupos que passaram a ter acesso às dependências das universidades que impôs essa demanda. Moreira destaca que

[...] a questão da igualdade e da diferença têm conquistado significativo espaço nos meios acadêmicos e políticos. Tem crescido a busca pela compreensão sobre como garantir a igualdade sem promover uma homogeneização e assegurar as diferenças dos grupos e dos indivíduos. [...] necessidade de assegurar a igualdade de direitos, ao mesmo tempo em que clama por respeito às diferenças individuais ou de grupos. (MOREIRA, 2018, p. 4).

Moreira (2018), Sacavino (2018) e Araújo (2018) publicaram nos Anais do ENDIPE 2018 que emergem nos últimos anos grupos com militâncias em torno de minorias historicamente subalternas e que tais grupos se posicionam frente ao contexto e à conjuntura (nacional e internacional) em que a lógica do mercado, os modos de produção e as perspectivas neoliberais ditam as relaçóes e as produçóes sociais. Moreira (2018, p. 3) destaca que, especialmente no Brasil, nas duas últimas décadas do século passado, "presenciamos o crescente protagonismo de grupos considerados minorias subalternas como as mulheres, os negros, os indígenas e os camponeses na busca por legitimidade e pelo reconhecimento dos seus direitos, dentre eles o direito à educação". Sacavino $(2018$, p. 4) analisa que a interculturalidade crítica é uma "prática política alternativa à geopolítica hegemônica, monocultural e mono-racional de construçáo do conhecimento, de 
distribuição do poder e de caráter social. Trata-se de uma ferramenta, uma estratégia e uma manifestação de uma maneira "outra" de pensar e agir". Ou seja, é uma perspectiva que exige articulação entre os direitos de igualdade e os direitos da diferença. De tal modo, a interculturalidade crítica vem sendo concebida como uma estratégia ética, política e epistêmica, na qual os processos educativos são fundamentais, pois possibilitam a problematização e o questionamento quanto a colonialidade presente na sociedade e na educação, e assim se busca desvelar o racismo e a racialização das relaçóes, promover o reconhecimento de diversos saberes e o diálogo entre diferentes conhecimentos, e assim, "combate-se as diferentes formas de deshumanização, promove-se a construção de identidades e o empoderamento de pessoas e grupos excluídos, favorecendo processos de construção coletiva na perspectiva de projetos de vida pessoal e de sociedades "outras" (SACAVINO, 2018, p. 5).

Reforça Moreira (2018, p. 4) que tal abordagem está associada a "projetos contra hegemônicos e emancipatórios", ou seja, projeto de resistência e luta, que e se apresentam como sendo mais adequados para a construção de sociedades democráticas e inclusivas, que articulem políticas de igualdade com políticas de identidade. Araújo (2018, p. 8) destaca que a interculturalidade crítica "parte do problema do poder, seu padrão de racialização e da diferença colonial e não, simplesmente cultural, que foi construída. Se dá a partir das pessoas que sofreram histórica submissão e subalternização. Tem raízes nos movimentos sociais, sentido contra hegemônico".

Apenas para registrar, destacamos que a intraculturalidade não foi conceitualmente explorada nas publicaçóes que discutiam temáticas em torno do multiculturalismo e interculturalidade. Compreende-se intraculturalidade como sendo o reconhecimento e o fortalecimento das próprias raízes culturais e identitárias, ou seja, a valorização dos saberes, tradiçôes e práticas dos povos de uma determinada sociedade, a valorização dos povos e culturas que compóem uma sociedade. Santos e Fetzner (2018, p. 4) ao analisarem o projeto de um curso de formação de professores destacam que "o caráter eminentemente político da Pedagogia relaciona propostas de educação intercultural com a educação popular, construindo uma rede de diálogo e confrontação de saberes que, além de promover a autoafirmação, fortalece movimentos intraculturais e interculturais". 
Para a construção desse artigo, foram analisadas, nos artigos selecionados (ENDIPE, 2018) as categorias: a) abertura; b) reconhecimento e redistribuição; c) democracia e justiça; d) preconceito, discriminação e monocultura; e) cultura, identidade e empoderamento.

\section{Abertura}

Um dos aspectos da interculturalidade crítica é a abertura a novas perspectivas teóricas, novos olhares e saberes (culturais, populares, ancestrais), novas formas de pensar, problematizar e realizar as práticas didáticopedagógicas. A categoria abertura se articula pelas categorias respeito e reconhecimento, no que se refere à condição humana, o que inclui as diferenças étnicas, culturais e linguísticas, enfim a toda diversidade. Apresenta-se como fundamental sensibilizar "o "olhar" do/a educador/a para as questóes suscitadas pelas diferenças culturais" (CANDAU, 2016, p. 815) e assim possibilitar a compreensão de que "mundo é um "arco-íris de culturas" (SANTOS, 1995) e construir outro "olhar" para o cotidiano escolar deve favorecer a superação do "daltonismo cultural" (STOER; CORTESÃO, 1999, p. 56). Há de ampliar o olhar e a percepção a fim de criar novas maneiras de situar-nos e intervir no dia a dia de nossas escolas e salas de aula.

Dentre os artigos analisados do Endipe/2018, pudemos identificar atitude de abertura nas reflexóes apresentadas que no intuito de afirmar a democracia, a cidadania e o direito de todos os cidadãos e cidadãs, assim apostam em iniciativas que trabalhem nos contextos educativos com temáticas vinculadas às

[...] relaçóes étnico-raciais, diversidade sexual, questôes de gênero, pluralismo religioso, relaçóes geracionais, culturas infantis e juvenis, entre outros, são temas que provocam tensóes, reações de intolerância e discriminação, assim como suscitam diversas iniciativas orientadas a trabalhá-las numa perspectiva que promova a afirmação democrática, o respeito mútuo, a aceitaçấo da diferença e a construção de uma sociedade em que todos e todas possam ser plenamente cidadãos e cidadãs (SACAVINO, 2018, p. 2).

Abertura às diferenças e abertura para o diálogo podemos identificar, por exemplo nas publicaçóes que propóem que "a abertura da escola às 
diferenças, bem como a preocupação dos educadores em promover diálogos entre saberes e culturas no cotidiano escolar são condições fundamentais para o desenvolvimento de práticas educativas críticas" (LUCINDA, 2018, p. 34). Já Oliveira (2018, p. 22) destaca que a prática educativa intercultural "permite um espaço de discussão, reflexão e problematização das diversidades presentes na sociedade contemporânea" e complementa apontando que é preciso construir uma educação capaz de compreender a complexidade das interaçóes humanas para que, dessa forma, superemos os preconceitos e as exclusóes socioculturais, criando "condições para que haja crescimento de todos os indivíduos e seus respectivos grupos, promovendo mudanças profundas na educação: currículo, metodologias, técnicas, instrumentos pedagógicos, formação de professores/as, quadros administrativos" (OLIVEIRA, 2018, p. $15)$.

De tal modo, conhecer e valorizar diferentes culturas possibilita "desvelar os pré- conceitos principalmente com relação a cultura de matriz africana, indígenas e as culturas populares que se manifestam nos espaços escolares" (RIBEIRO; CAMPOS, 2018, p. 30).

Sacavino enfatiza que os processos educativos são fundamentais, pois

[...] através deles se questiona a colonialidade presente na sociedade e na educação, se desvela o racismo e a racialização das relaçóes, se promove o reconhecimento de diversos saberes e o diálogo entre diferentes conhecimentos, combate-se as diferentes formas de deshumanização, promove-se a construção de identidades e o empoderamento de pessoas e grupos excluídos, favorecendo processos de construçáo coletiva na perspectiva de projetos de vida pessoal e de sociedades "outras" (SACAVINO, 2018, p. 5).

No que se refere à construção de identidades abertas, Santos (2018, p. 141) reconhece que todos os alunos e alunas "possuem conhecimentos construídos socialmente que devem ser ampliados e transformados em função da construção de novas identidades abertas às diferenças e aos desafios impostos pela sociedade excludente e desigual na qual estamos inseridos/as."

Cardoso Junior (2018, p. 15) argumenta em prol de um enfoque aberto na construção do coneito de arte, capaz de questionar e desconstruir a perspectiva da educação monocultural, uma vez que valoriza a promoção da educação intercultural, que "valoriza uma conceituação aberta e não 
excludente da arte como condição necessária para a interação dos conhecimentos artísticos consagrados pela cultura escolar e aqueles oriundos da estética do cotidiano dos/as alunos/as e do entorno da escola".

$\mathrm{Na}$ publicação de Valentim (2018, p. 19), foi possível identificar metodologicamente como a docente trata a didática na perspectiva intercultural crítica, bem como os desafios por ela enfrentados. Nesse sentido, relata que "tocar na questão racial brasileira é, ainda, gerar desconforto em qualquer ambiente, no bar ou na universidade e, em minha classe, não é diferente. No Brasil, o racista é sempre 'o outro'." A autora entende que cabe a ela, enquanto professora ter "[...] uma didática que se pretenda intercultural enfrentar o desconforto, problematizar, deixar vir à tona eventuais conflitos a fim de contribuir para a desconstrução desse 'mito' deletério à educação para as relaçóes raciais que temos o dever de desenvolver.” É possível verificar a intencionalidade docente de trabalhar questóes relativas ao reconhecimento e à valorização das diferenças culturais nos contextos escolares, conforme nos orienta Candau (2012).

Portanto, entende-se que a abertura consiste em questionar sobre o que está posto, é abrir para outros/novos paradigmas, outros/novos olhares que envolvem o campo da educação, principalmente, neste caso, a didática. É a partir desses novos olhares, que é possível se ter novas posturas diante das diferenças étnicas, culturais e linguísticas e, consequentemente, ter uma aceitação positiva da diversidade, por meio do respeito mútuo.

\section{Reconhecimento e redistribuiçáo}

A análise das categorias reconhecimento e redistribuição são fundamentais para a educação na perspectiva intercultural crítica. Consoante Candau (2018, p. 276-277), náo basta "reconhecer a diversidade cultural e promover diferentes expressóes culturais, numa abordagem de caráter muitas vezes celebratório. Estas iniciativas tratam, em geral, a diversidade cultural como se fosse um dado 'natural' e com isso, verifica-se uma visão essencialista das culturas". Sendo que o fundamental seria propor debate, reconhecimento, respeito e aceitação do dissenso, da contradição e da liberdade de compreensão e de expressão. 
Reconhecimento foi uma categoria abordada nos textos selecionados e analisados do Endipe (2018). Ao todo, foram encontradas 11 citaçôes que contemplaram este aspecto. Para Santos e Fetzner,

[...] a potencialidade de um autêntico diálogo intercultural - aquele que leva em conta as assimetrias existentes. Segundo eles, pode-se, assim, encontrar soluçôes impossíveis para uma cultura moderna única. Estes autores destacam o caráter político do conceito ao colocar em contato diferentes conhecimentos, visóes de mundo, modos de ser e de viver e ao permitir o diálogo que pode tornar visíveis mecanismos de poder em que algumas culturas se sobrepóem às outras, subalternizando-as (SANTOS; FETZNER, 2018, p. 4-5).

Reafirma-se, portanto, a necessidade do diálogo para que prevaleça a criticidade e não uma visão essencialista, pois náo basta apenas reconhecer, é preciso respeitar e aceitar o dissenso. Outro aspecto fundamental e que está relacionado às açóes afirmativas consiste na redistribuição, ou seja, na inclusão da articulação entre redistribuiçáo e reconhecimento, na valorização do reconhecimento das minorias estimulando políticas de redistribuição, como é o caso das cotas e bolsas.

De acordo com a análise feita, apenas duas citaçôes abrangiam a redistribuição de modo direto e literal. Entendeu-se que muito se argumentou sobre a necessidade de reconhecimento, mas desproporcionalmente a redistribuição foi pouco abordada nas publicaçóes analisadas. Oliveira (2018) focou na valorização do reconhecimento de minorias, especificamente sobre a cultura dos quilombolas, mas não fez menção à redistribuição, enquanto políticas, ou açóes afirmativas. Já Valentim $(2018$, p. 17) ressaltou elementos que compóem o conceito de políticas públicas, que considera como "relaçóes entre os processos educacionais e os contextos político-sociais em que se inserem; ao reconhecimento dos diferentes movimentos sociais presentes na sociedade brasileira; à defesa da articulação entre políticas de reconhecimento e de redistribuição $[. .$.$] ".$

Apresenta-se como necessário pensar sobre ações afirmativas, uma vez que, para Candau (2017), elas correspondem "a medidas, políticas, projetos que focalizam grupos sociais inferiorizados e marginalizados, na perspectiva da sua inserção na sociedade". Nas publicaçóes analisadas nessa pesquisa, 
verificou um movimento tímido no que se refere à relação entre reconhecimento, redistribuição, ações afirmativas e interculturalidade crítica.

Para Streck apud Sacavino (2018, p. 4) “cabe reconhecer que os caminhos da emancipação são diversos e que uma sociedade democrática não pode prescindir dessa ecologia cognitiva, reconhecendo a diversidade de sujeitos e de lugares e formas de produção de conhecimentos". Partindo deste entendimento, é possível perceber a relação entre reconhecimento, redistribuição e políticas públicas educacionais que visem e promovam maior democracia (CANDAU, 2017).

\section{Democracia e justiça}

No que tange a interculturalidade nos processos educativos, Candau (2016) afirma que a construção de sociedades mais democráticas é percebida quando a criticidade, proposta pela interculturalidade, é inserida no cotidiano escolar.

A categoria democracia e aspectos relacionados a ela foram objeto de análise nesta pesquisa e destaca-se a: a) construção de novos modos de relaçáo social e maior democracia; b) busca pelo fortalecimento de processos democráticos; c) articulação democrática entre os diferentes grupos sociais que integram um determinado país; d) fortalecimento da ação coletiva; e) articulação entre açóes da escola com outros atores sociais, a fim de contribuir para a construção de uma educação e uma sociedade mais igualitária, justa, inclusiva e democrática.

Com relação a uma proposta mais democrática que esteja inclusa no âmbito escolar, o texto de Sacavino (2018, p. 2) explicita que,

Relações étnico-raciais, diversidade sexual, questões de gênero, pluralismo religioso, relaçóes geracionais, culturas infantis e juvenis, entre outros, são temas que provocam tensôes, reaçóes de intolerância e discriminação, assim como suscitam diversas iniciativas orientadas a trabalhá-las numa perspectiva que promova a afirmação democrática, o respeito mútuo, a aceitação da diferença e a construção de uma sociedade em que todos e todas possam ser plenamente cidadáos e cidadâs (SACAVINO, 2018, p. 2). 
Portanto, verifica-se a importância de trabalhar em ambientes educacionais questóes étnico-raciais, de gênero, pluralismo religioso, diversidade sexual, dentre outras temáticas e conceitos relevantes para a problematização, reflexão e compreensão sobre a realidade e a condição humana.

Os ambientes educacionais deveriam refletir sobre açóes coletivas, sobre movimentos sociais, com o desafio de escutar e dar voz a diferentes atores sociais. Para Valentim (2018, p. 20), os educadores e educadoras ao aceitarem o desafio de pensar em "vínculos entre educação e identidade negra seja reconhecer que qualquer intervenção pedagógica a ser feita não pode desconsiderar que, no Brasil, vivemos sob o mito da democracia racial e padecemos de um racismo ambíguo." Isto é, nega-se a existência de preconceito, o que é uma falácia, sendo fundamental tais discussões em âmbito escolar, como propóe a interculturalidade crítica.

A articulação entre educação, democracia e justiça se fez presente nas publicações analisadas. No que se refere à justiça, identificou-se a afirmação da justiça - social, econômica, cognitiva e cultural, assim como da construção de relaçôes igualitárias entre grupos socioculturais e da democratização da sociedade, por meio de políticas que articulam direitos da igualdade e da diferença. É possível destacar que,

[...] o que estamos querendo trabalhar é, ao mesmo tempo, negar a padronizaçáo e também lutar contra todas as formas de desigualdades presentes na nossa sociedade. Nem padronização nem desigualdade. E sim, lutar pela igualdade e pelo reconhecimento das diferenças. A igualdade que queremos construir assume a promoção dos direitos básicos de todos e todas. No entanto, esses todos não são padronizados, não são os "mesmos". Tem que ter as suas diferenças reconhecidas como elemento de construçáo da igualdade (CANDAU apud LUCINDA, 2018, p. 29).

A categoria justiça pode ser identificada no texto citado acima, dada a argumentação em torno da luta contra as desigualdades e a padronização.

Da mesma forma, a escola é um espaço que propicia uma formação na qual a consciência crítica torna-se fundamental. Isso contribui para que os padróes estipulados socialmente sejam questionados, problematizados, refletidos. Santos e Fetzner afirmam que, 
a escola, como espaço por excelência de formação, deve proporcionar a percepção de novos horizontes de qualidade de vida, por meio do desenvolvimento da consciência crítica, da constituição de espaço de diálogo que questiona o padrão de exclusão e exploração das populaçóes economicamente menos favorecidas. Ao colocar em diálogo os diferentes sujeitos que por ela passam, pode ajudá-los a reconhecer e edificar outras formas de existência - mais justas (SANTOS; FETZNER, 2018, p. 4).

Portanto, a partir do exposto, entende-se que a interculturalidade visa trabalhar nas escolas e salas de aulas um novo olhar, um olhar crítico diante da diversidade e em prol de uma sociedade mais democrática, assim como justa.

\section{Preconceito e discriminaçáo e o caráter monocultural}

Conforme Santos e Fetzner (2018, p. 4), diversos autores latinoamericanos vêm ressaltando que tem sido também por meio da educação que "uma cultura que se apresenta como dominante busca negar, menosprezar e excluir outras, na tentativa de impor um projeto cultural”. Tais autores argumentam que um projeto eurocêntrico vem historicamente desconsiderando a história, as culturas, as cosmogonias e as epistemologias latino-americanas. Moreira (2018) destaca que a escola etnocêntrica, ao privilegiar determinados saberes, em detrimento de outros, acaba por silenciar e invisibilizar os saberes e as culturas afro-brasileiras e indígenas.

A perspectiva da educaçâo intercultural vem justamente questionar e desconstruir o caráter monocultural e monoracial, o etnocentrismo e a colonialidade presentes nas escolas, nos currículos e nas políticas educativas. Nesta perspectiva, os autores que publicaram no Endipe/2018 defendem a construção e o desenvolvimento de processos educacionais que desconstruam os processos que inferiorizam e desvalorizam os conhecimentos oriundos dos grupos sociais subalternizados.

Trabalhar a partir da perspectiva intercultural implica o reconhecimento dos preconceitos e da discriminação racial no âmbito da sociedade, para assim proceder o enfrentamento dessas questóes, que no caso brasileiro também estruturam as desigualdades. 


\section{Cultura, identidade e empoderamento}

Conforme Candau,

A interculturalidade crítica fortalece a construção de identidades dinâmicas, abertas e plurais, assim como questiona uma visão essencializada de sua constituiçấo. Potencia os processos de empoderamento, principalmente de sujeitos e atores inferiorizados e subalternizados e a construção da autoestima e estimula a construção da autonomia num horizonte de emancipação social. (CANDAU, 2019, p. 280).

Nesta perspectiva, os autores que publicaram no Endipe/2018, ao abordarem o componente da construçâo das identidades culturais plurais, de sujeitos individuais e coletivos, e os processos de empoderamento de pessoas e grupos sociais que historicamente tiveram menos poder na sociedade, ressaltam a urgência de desenvolver formação docente, práticas pedagógicas e propostas curriculares desde uma perspectiva intercultural que "deem visibilidade às culturas e histórias locais e que possam, assim, fortalecer politicamente os grupos subalternizados, excluídos e explorados" (SANTOS; FETZNER, 2018, p. 2). Desse modo, a diversidade cultural que faz parte do cotidiano dos estuda ntes, as histórias de vida e da construção de diferentes comunidades socioculturais são elementos fundamentais, que ao serem problematizados permitem tornar visíveis os mecanismos de dominação de algumas culturas sobre às outras.

Os autores assinalam que para que ocorra o resgate de processos de construção das identidades culturais e o empoderamento dos grupos subalternizados é importante buscar recuperar e reposicionar as histórias e as memórias ancestrais esquecidas, silenciadas e oprimidas das populaçóes historicamente subalternizadas. Sendo assim, é urgente a construção dessas memórias ancestrais dos povos ameríndios e afro-brasileiros na nossa história, assim como é preciso recolocar e remapear essas cartografias, o que exige descolonizar e decolonizar corpos e mentes (ARAÚJO, 2018, p. 8).

Araújo (2018, p. 5) destaca a importância do ensino de História abordar "memórias outras, narrativas outras que permitam revelar, desvelar a ação e construção do mundo pelo viés de grupos socialmente e economicamente desvalorizados e silenciados por práticas depredadoras, 
dominantes e elitizadas". Santos (2018) ressalta que na perspectiva da educação intercultural, o currículo de Educação Física abre espaço para o estudo das práticas sociais e corporais pertencentes aos grupos desfavorecidos, a exemplo de manifestaçóes como a capoeira, o maculelê, estilos de dança como o samba e o funk, e brincadeiras populares como as cantigas de roda; assim como "reconhece que todos os alunos e alunas possuem conhecimentos construídos socialmente que devem ser ampliados e transformados em função da construção de novas identidades abertas às diferenças e aos desafios impostos pela sociedade excludente e desigual na qual estamos inseridos/as" (SANTOS, 2018, p. 34). Moreira (2018) também ressalta que é preciso buscar visibilizar as manifestaçôes que afirmam mais fortemente a cultura afro-brasileira e indígena. Valentim (2018) destaca que o depoimento oral de alunos negros em relação ao racismo no ensino superior, por sua natureza disruptiva e problematizadora, podem levar às trocas entre sujeitos com identidades raciais diferentes e, assim, contribuir para desconstruir o "mito da democracia racial" e para visibilizar os privilégios e subalternidades sociais.

Cardoso Júnior (2018), a partir da experiência do Colégio Pedro II que relaciona interculturalidade e ensino de Artes Visuais, ressalta que o trabalho desenvolvido na instituição com o ensino $\mathrm{d}$ as artes dos povos indígenas, africanos e afro-brasileiros "incorporou o entendimento das identidades culturais plurais de sujeitos individuais e coletivos, com disposição de promover o empoderamento de sujeitos socialmente subalternizados" (CARDOSO JÚNIOR, p. 23), assim como buscou "descontruir a ideia essencializada de índio e de negro com a consideração da existência de várias etnias, suas especificidades, formas de vida e percepção do mundo em diálogo com a produção artística" (CARDOSO JÚNIOR, p. 18-19).

Destaca-se, conforme Grando e Stroher (2018, p. 11), que "as interlocuçóes culturais presentes nas atividades educacionais permitem ampliar as possibilidades de entender o outro a partir da sua identidade característica". Araújo (2018, p. 4), em referência ao livro Documentos de identidade (1999) de Tomaz Tadeu da Silva, salienta "que só educamos quando metamorfoseamos subjetividades empoderando novas identidades". E como destaca Oliveira (2018, p. 18), "o docente comprometido em reforçar as identidades particulares e diferentes culturas, possibilita em seu fazer pedagógico a transformação social”. 


\section{Consideraçóes finais}

A presente pesquisa possibilitou compreender que dentre os trabalhos publicados no Endipe (2018) há esforços teóricos, reflexivos e práticos insurgentes rumo à interculturalidade crítica na educação (CANDAU, 2019) e nessa perspectiva visam: a) fortalecer a construção de identidades dinâmicas, abertas e plurais; b) questionar uma visão essencializada de sua constituição; c) potencializar processos de empoderamento, principalmente de sujeitos e atores inferiorizados e subalternizados e a construção da autoestima e estimular a construção da autonomia num horizonte de emancipação social; d) refletir sobre educação, interculturalidade e categorias emergentes (abertura, reconhecimento, redistribuição, preconceito, discriminação, pluralidade cultural, identidade, empoderamento, justiça, democracia, dentre outras).

Assim, a partir das análises das publicaçóes do Endipe/2018, verifica-se a importância de práticas pedagógicas insurgentes. Isso significa, de acordo com Candau (2020, on-line), que é preciso olhar, tanto para os professores, quanto para a escola. Em relação aos professores e professoras, entende-se que há uma nova demanda de entender que tipo de conhecimento os estudantes de hoje têm, o que estão aprendendo. Tanto crianças, adolescentes e jovens estão interagindo, contemporaneamente, de modos diferentes com as pessoas que convive, e o professor, muitas vezes, ainda tem trabalhado de modo distinto ao que esses alunos vivem.

Já a escola, precisa se reinventada. Conforme afirma Candau (2020, on-line) "Não existe uma maneira de fazer escola única, padronizada, a melhor[...]", por isso, a concepção de um espaço fechado, com uma organização de tempo, ano letivo e formas de avaliação repetivas, não podem estar engessadas. Esta reinvençao da escola passa pelos conhecimentos/conteúdos. Consequentementemente, os conteúdos escolares, que são importantes, devem ser desnaturalizados, pois estes ainda são, em sua maior parte, considerados como fixos e inalteráveis, sem a possibilidade de abrir espaço para discussão de outros conhecimentos, que também são importantes. Torna-se fundamental o exercício democrático de um dialogo que dê voz a todos. Uma escola que permita a expressão cultural, em que as pessoas possam se vestir conforme suas culturas, que hajam pinturas nas paredes que sejam afro, indígenas, grafites urbanos, de movimento sociais, por 
exemplo. A escola deve um espaço que se conviva com a pluralidade de manisfetaçôes, isto é, que as diferenças se tornem riquezas, não desigualdades.

Em suma, ressaltar-se, a necessidade de criar alternativas, ter novos olhares, ter a abertura e a ousadia de experimentar outros conteúdos em sala de aula. A escola precisa ter novos posicionamentos nos quais priorize o desengessamento das práticas pedagógicas, propondo uma nova cultura escolar em que as diferenças também sejam valorizadas; que mais identidades sejam destacadas, que haja diálogo, questionamentos, novas posturas nas relaçôes interpessoais. É repensar, respeitar, se reposicionar. É tomar novos caminhos para se chegar, de fato, à interculturalidade crítica.

\section{Referências}

CANDAU, V. M. 15/07 - 17h - Sl01 - Práticas Pedagógicas Insurgentes: XX ENDIPE Rio 2020. Youtube, 15 jul. 2020. Disponível em: https://www.youtube.com/watch?v=d065Sf-swnk. Acesso em: 22 jul. 2020.

. Educação intercultural e práticas pedagógicas. In: SILVA, Marco; ORLANDO, Cláudio; ZEN, Giovana. Didática: abordagens teóricas contemporâneas. Salvador: EDUFBA, 2018. p. 275-287.

- Abcedário de Educação e Interculturalidade com VERA CANDAU. Youtube. 26 dez. 2017. Disponível em: https://www.youtube.com/watch?v=0OWPYJUaT10. Acesso em: $06 \mathrm{mar}$. 2020 .

. Cotidiano escolar e práticas interculturais. Cadernos de Pesquisa. v. 46 n.161, p. 802-820, jul./set., 2016.

- Construindo Práticas Escolares Interculturais e Formação Docente. Anais. XVII ENDIPE Fortaleza, 2014.

Diferenças culturais, interculturalidade e educação em direitos humanos. Educ. Soc., Campinas, v. 33, n. 118, p. 235-250, mar., 2012.

- Diferenças culturais, cotidiano escolar e práticas pedagógicas. Curriculo sem Fronteiras, v.11, n.2, p.240-255, jul./dez., 2011. 
CANDAU, V. M. Educação Escolar e Cultura(s): multiculturalismo, universalismo e currículo; In: - (Org.) Didática: questôes contemporâneas. Rio de Janeiro: Ed. Forma \& Ação, 2009.

. Direitos humanos, educação e interculturalidade: as tensôes entre igualdade e diferença. Revista Brasileira de Educação, v.13, n. 37, 2008.

CARDOSO JUNIOR, Wilson. Interculturalidade, currículo e práticas pedagógicas no ensino de artes visuais do Colégio Pedro II. In: ARAÚJO, Helena M. M.; JUNIOR, Wilson C.; SANTOS, Ana Paula da S. Educação Intercultural e o ensino de História, Artes Visuais e Educação Física: problematização de concepções e práticas por uma educação outra. PAINEL 100190. ANAIS XIX ENDIPE, 2018.

LUCINDA, Maria da Consolação. Reconhecimento do direito à diferença e luta pela igualdade na escola - a importância do Boletim direitos humanos na sala de aula. Painel 98586. ANAIS XIX ENDIPE, 2018.

MOREIRA, Edna Souza. A licenciatura em pedagogia e as perspectivas contemporâneas: reflexôes inspirados no multiculturalismo. In: A abordagem didática contemporânea nos cursos de formação inicial: interface entre multiculturalismo e formação docente. Painel 100211. ANAIS XIX ENDIPE, 2018.

OLIVEIRA, Bruna Maria de. Educação Quilombola, práticas corporais e formação de professores na perspectiva da Educação Física Intercultural. Painel 99746. ANAIS XIX ENDIPE, 2018.

RIBEIRO, Sueli de Fátima Xavier; CAMPOS, Neide da Silva. Formação de professores de educação física e prática pedagógica: perspectiva das relaçóes étnico-raciais e a educação intercultural. Painel 99746. ANAIS XIX ENDIPE, 2018.

SACAVINO, Susana B.; VALENTIN, Daniela Drelich; LUCINDA, Maria da Consolação. Práticas Pedagógicas e educação intercultural: desvelando conceitos para transformar. Painel 98586. ANAIS XIX ENDIPE, 2018.

SANTOS, Ana Paula da Silva. O currículo da educação física no ensino médio: um olhar a partir da educação intercultural. PAINEL 100190. ANAIS XIX ENDIPE, 2018. 
SANTOS, Vera Regina Souza dos; FETZNER, Andréa Rosana. A interculturalidade como proposta potencial para o enfrentamento dos desafios educacionais contemporâneos. Pôster 99645. ANAIS XIX ENDIPE, 2018.

SANTOS. Boaventura Sousa. Modernidade, identidade e a cultura de fronteira. Tempo Social: Revista de Sociologia, São Paulo, v. 5, n. 1-2, p. 3152, 1993.

SEN, Amartya. O racha do multiculturalismo. Suplemento Mais. Folha de Sáo Paulo; 17 de setembro 2006.

STOER, Stephen; CORTESÃO, Luisa. "Levantando a pedra”: da pedagogia inter/multicultural às políticas educativas numa época de transnacionalização. Porto: Afrontamento, 1999.

XAVIER, Giseli Pereli de Moura; IVENICKI, Ana; SILVA JUNIOR, Paulo Melgaço da. Entre masculinidades, gênero e raça: $A$ pesquisa ação inter/multicultural no contexto da prática pedagógica. Painel 97176. ANAIS XIX ENDIPE, 2018.

Recebido em: 02 ago. 2020

Aceito em: 19 ago. 2020 